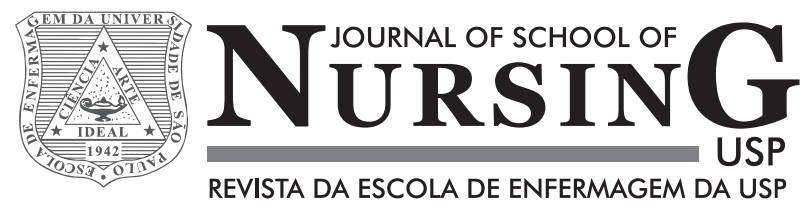

\title{
Heart failure as a predictor of functional dependence in hospitalized elderly
}

\author{
Insuficiência cardíaca como preditor de dependência funcional em idosos hospitalizados \\ Insuficiencia cardiaca como pronosticador de dependencia \\ funcional en ancianos hospitalizados
}

Sara de Oliveira Xavier ${ }^{1}$, Renata Eloah de Lucena Ferretti-Rebustini ${ }^{2}$, Eduesley Santana-Santos ${ }^{3}$, Paola Alves de Oliveira Lucchesi $^{4}$, Karine Generoso Hohl ${ }^{5}$

\footnotetext{
${ }^{1}$ Universidade de São Paulo, Escola de Enfermagem, Programa de Residência em Enfermagem em Cardiopneumologia de Alta Complexidade, São Paulo, SP, Brazil.

${ }^{2}$ Universidade de São Paulo, Escola de Enfermagem, Departamento de Enfermagem Médico-Cirúrgica, São Paulo, SP, Brazil.

${ }^{3}$ Universidade de São Paulo, Faculdade de Medicina, Hospital das Clínicas, Instituto do Coração, São Paulo, SP, Brazil.

${ }^{4}$ Instituto do Câncer do Estado de São Paulo, São Paulo, SP, Brazil.

${ }^{5}$ Universidade de São Paulo, Faculdade de Medicina, Hospital das Clínicas, Instituto de Psiquiatria, São Paulo, Brazil.
}

\begin{abstract}
Objective: Identify whether Heart Failure (HF) is a predictor of functional dependence for Basic Activities of Daily Living (BADL) in hospitalized elderly. Methods: We investigated medical records and assessed dependence to BADL (by the Katz Index) of 100 elderly admitted to a geriatric ward of a university hospital. In order to verify if HF is a predictor of functional dependence, linear regression analyzes were performed. Results: The prevalence of HF was 21\%; $95 \%$ of them were dependent for BADLs. Batbing was the most committed ADL. HF is a predictor of dependence in hospitalized elderlies, increasing the chance of functional decline by 5 times (95\% CI, 0.94-94.48), the chance of functional deterioration by 3.5 times $(95 \% \mathrm{CI}, 1.28-11.66$; $\mathrm{p}<0.02)$ and reducing 0.79 points in the Katz Index score $(p<0.05)$. Conclusion: HF is a dependency predictor of $\mathrm{ADL}$ in hospitalized elderly, who tend to be more dependent, especially for bathing.
\end{abstract}

\section{DESCRIPTORS}

Heart Failure; Aged; Hospitalization; Activities of Daily Living; Baths.

\section{Corresponding author:}

Renata Eloah de Lucena Ferretti-Rebustini

Escola de Enfermagem da Universidade de São Paulo

Av. Dr. Enéas de Carvalho Aguiar, 419 -

Cerqueira Cesar

CEP 05403-000 - São Paulo, SP, Brazil

reloah@usp.br
Received: 03/18/2015

Approved: 06/10/2015 


\section{INTRODUCTION}

Heart Failure (HF) is an increasingly common condition among the elderly, as its prevalence increases with age $^{(1)}$. It is estimated that an increase in the incidence and prevalence of HF in individuals aged between 60 and 80 years will occur in the coming years, causing the number of new cases to double and the number of cases to be about 10 times higher ${ }^{(1)}$. In addition to representing one of the major causes of morbidity and mortality among the elderly, HF is a major cause of hospitalization and demand for emergency services among the elderly in Brazil and throughout the world ${ }^{(2-3)}$.

Clinical manifestations of HF in the elderly may be different from those observed in adults, depending on the specific aging characteristics ${ }^{(4)}$. Still, its presence is associated with states of greater dependence due to the clinical and functional repercussions of $\mathrm{HF}^{(5-6)}$.

Functional dependence in elderly with HF may be due to the disease itself, but it can also be associated with the hospitalization. It is known that fully independent elderly may need aid for one or more basic activities of daily living during hospitalization ${ }^{(6)}$.

Hospitalization is associated with the patient having an increase in dependence, causing the identification of individuals with increased risk of functional loss to be a routine action in nursing care practice. Early identification of elderly at higher risk of dependence can help to minimize the adverse consequences of hospitalization and therefore individualized nursing actions will be able to meet care demands compatible with the functional performance of the elderly. HF was previously identified as a risk factor for greater dependence in elderly ${ }^{(6-7)}$.

There were no national studies that could identify whether $\mathrm{HF}$ is a dependence predictor in hospitalized elderly. Also, no studies were found indicating the impact of $\mathrm{HF}$ in functional loss of hospitalized elderly. Thus, the present study aims to identify the functional profile of hospitalized elderly with HF and verify whether $\mathrm{HF}$ is a dependence predictor for ADL in hospitalized elderly.

\section{METHOD}

This is an epidemiologic, observational cross-sectional study approved by the Local Ethics Committee ( $\mathrm{N}^{\circ}$ 603527-0) performed according to national research requirements involving human subjects.

In the period from April to August 2014, all seniors who were admitted to the geriatric ward of a large university hospital in São Paulo were investigated. All individuals older than or equal to 60 years and who consented to participate in the study by signing the Informed Consent Form were included in the study. In cases of illiteracy, consent was formalized by a legal representative.

Admission records contained in the participant's medical files were analyzed and a functional bedside evaluation of the elderly was conducted. Demographics (sex and age) and Clinical data (admission diagnosis, previous diagnosis of HF, history of morbidities, amount of prescription drugs and Left Ventricular Ejection Fraction) were extracted from medical records.

Clinical characterization of $\mathrm{HF}$ cases was made by the New York Heart Association Functional Class (NYHA-FC) and by the Left Ventricular Ejection Fraction (LVEF\%), estimated by Teicholz method (LVEF\% $\leq 55 \%$; LVEF\% > 55\%) obtained from a Transthoracic Echocardiogram performed in the last six months prior to admission. As there was no record of the NYHA-FC in the medical records, it was estimated at the time of the evaluation. Thus, particpants were classified on a scale ranging from I to IV, as follows: I) absence of dyspnea in activities of daily living; II) symptoms triggered by routine activities; III) symptoms triggered with minimal exertion or lower intensity activities; and IV) symptoms at rest ${ }^{(8)}$.

Functional evaluations were performed at bedside by the investigator through the application of the Katz Index ${ }^{(9)}$. The application time was approximately 10 minutes.

Katz Index assesses the functional independence for six activities of daily living: bathing, dressing, feeding, toileting, transferring and continence. For the present study, elderly received 1 point when they could perform the activity independently (without supervision, direction or assistance) and received score zero when they presented dependence for such activity (needed supervision, direction or assistance). The total score of the scale ranges from zero to six points.

Katz index score was obtained by the sum of points obtained in each of the activities. For classifying the level of dependency, the elderly were categorized into: independent (six points), partially dependent (three to five points) and totally dependent (zero to two points) $)^{(10)}$.

Data were analyzed using descriptive (indicating measures of central tendency and dispersion), and analytic statistics. For analysis we used the Student's T-test (for comparison of means) and Fisher's Exact Test (for analysis of associations between nominal variables). To verify whether $\mathrm{HF}$ is a predictor of functional dependence for ADLs in elderly, linear regression analyzes were performed, taking the score on the Katz index as the dependent variable and $\mathrm{HF}$ as an independent variable. $P$ value was set at 0.05 and all tests were two-tailed. The software used was SPSS version 21.

\section{RESULTS}

We invited 111 elderlies admitted into the geriatric ward during the study period to participate in the study, and of these 11 refused. Thus, the sample consisted of 100 elderly, mostly women $(n=56)$. The mean age of participants was $79.2 \pm 7.5$ years (60-96 years). The mean age was $80.4 \pm 7.6$ years for women and $77.7 \pm 7.1$ years for men. Women were on average almost three years older than men, but this difference was not statistically significant $(\mathrm{p}<0.70)$. The general characteristics of the sample due to the presence of heart failure are shown in Table 1.

Over 50 admission causes were mapped. Most of the elderly $(82 \%)$ were admitted for treatment and a smaller part for diagnostic purposes or exams (18\%). Only two elderly had HF as a cause for admission, which were not excluded 
from statistical analysis due to a clinical complexity evaluation similar to the whole sample. Weight loss and dyspnea were the most associated admission symptoms, accounting for $4 \%$ and $3 \%$ of cases, respectively.

Table 1 - Characterization of the sample according to demographic and clinical variables, according to the presence of heart failure (HF) - São Paulo, SP, Brazil, 2015.

\begin{tabular}{lcccc}
\hline & Total & No HF & With HF & p-value* \\
\hline General characteristics of the sample $(n=100)$ & & & & \\
Sex $[\mathrm{n}(\%)]$ & $100(100.0)$ & $79(79.0 \%)$ & $21(21.0 \%)$ & 0.317 \\
Age $($ mean \pm SD) & $79.2 \pm 7.5$ & $78.9 \pm 7.6$ & $80.7 \pm 7.0$ & 0.008 \\
Comorbidities & $4.0 \pm 1.8$ & $3.8 \pm 1.7$ & $4.9 \pm 1.7$ & 0.131 \\
Prescribed medication & $10.4 \pm 3.5$ & $10.1 \pm 3.2$ & $11.4 \pm 4.3$ & 0.007 \\
Katz index (mean \pm SD) & $2.6 \pm 2.2$ & $2.9 \pm 2.3$ & $1.5 \pm 1.9$ & \\
\end{tabular}

\section{Characterization of HF cases $(n=21)$}

Personal history of HF $[\mathrm{n}(\%)]^{+}$

NYHA Functional Class $[\mathrm{n}(\%)]^{++}$

$\begin{array}{ll}\text { FCI } & 3(15) \\ \text { FCII } & 9(42) \\ \text { FCIII } & 6(28) \\ \text { FCIV } & 3(15)\end{array}$

LVEF\% $[\mathrm{n}(\%)]^{++}$

$\begin{array}{ll}\leq 55 \% & 13(61.9) \\ >55 \% & 8 ;(38.1)\end{array}$

${ }^{*}$ Student's t-test ${ }^{\dagger}$ in relation to total; ${ }^{+1}$ in relation to $\mathrm{HF}$ group.

The mean number of comorbidities was $4.0 \pm 1.8$, where fifteen elderly presented from four to seven diseases. Among the comorbidities, the main cardiovascular risk factors were systemic hypertension (70\%), diabetes mellitus (61\%), dyslipidemia (52\%), obesity (24\%) and smoking (22\%). In $23 \%$ of cases, a diagnosis of depression was also observed. Nineteen participants had up to 15 drugs in prescription, with a mean of $10.4 \pm 3.5$ prescribed drugs.

We found that $21 \%$ of the elderlies had HF in their medical personal history. Most of the them were classified as NYHA-FC II and III with LVEF\% lower than or equal to $55 \%$. Table 1 shows the distribution of individuals according to NYHA-FC and LVEF\%.

The mean score of Katz index was $2.6 \pm 2.2$ points lower among women $(2.3 \pm 2.0)$ than among men $(3.0 \pm 2.5)$. It was observed that 54 of the elderly were totally dependent, 29 of the elderly presented partial dependence, and 17 were independent for ADL. Therefore, 83 participants had some level of dependence.

In general, elderly patients with HF had more comorbidities and were more dependent than those who had no personal history of HF (Table 1). When evaluating the association between level of dependence and the sex of the elderly without previous diagnosis of $\mathrm{HF}$, it was observed that only two $(2.5 \%)$ women were independent, while 43 had some level of dependency. Older women were more dependent for ADL than men $(\mathrm{p}<0.000)$. There was no statistically significant difference between the level of dependence and sex of elderly patients with a previous diagnosis of HF ( $\mathrm{p}<0.441$ ), as shown in Table 2.

Among the participants previously diagnosed with $\mathrm{HF}$, it is noteworthy that $16(76.2 \%)$ were totally dependent

Table 2 - Association between level of dependence, previous diagnosis of heart failure and sex in hospitalized elderly - São Paulo, SP, Brazil, 2015.

\begin{tabular}{|c|c|c|c|c|c|c|c|}
\hline & & & & \multicolumn{2}{|c|}{ Sex } & \multirow{2}{*}{ Total } & \multirow{2}{*}{$p$-value* } \\
\hline & & & & Men & Women & & \\
\hline \multirow{4}{*}{$\begin{array}{l}\text { No previous } \\
\text { diagnosis of HF }\end{array}$} & \multirow{4}{*}{ Dependency Level } & Totally dependent & $\mathrm{n}(\%)$ & $13(16.5 \%)$ & $25(31.6 \%)$ & $38(48.1 \%)$ & \multirow{4}{*}{0.000} \\
\hline & & Partially dependent & $\mathrm{n}(\%)$ & $7(8.9 \%)$ & $18(22.8 \%)$ & $25(31.6 \%)$ & \\
\hline & & Independent & $\mathrm{n}(\%)$ & $14(17.7 \%)$ & $2(2.5 \%)$ & $16(20.3 \%)$ & \\
\hline & & Total & $\mathrm{n}(\%)$ & $34(43.0 \%)$ & $45(57.0 \%)$ & $79(100 \%)$ & \\
\hline \multirow{4}{*}{$\begin{array}{l}\text { With previous } \\
\text { diagnosis of HF }\end{array}$} & \multirow{4}{*}{ Dependency Level } & Totally dependent & $\mathrm{n}(\%)$ & $7(33.3 \%)$ & $9(42.9 \%)$ & $16(76.2 \%)$ & \multirow{4}{*}{0.441} \\
\hline & & Partially dependent & $\mathrm{n}(\%)$ & $3(14.3 \%)$ & $1(4.8 \%)$ & $4(19.0 \%)$ & \\
\hline & & Independent & $\mathrm{n}(\%)$ & $0(0 \%)$ & $1(4.8 \%)$ & $1(4.8 \%)$ & \\
\hline & & Total & $\mathrm{n}(\%)$ & $10(47.6 \%)$ & $11(52.4 \%)$ & $21(100 \%)$ & \\
\hline
\end{tabular}

* Fisher's exact test. 
and 4 were partially dependent, while only one (4.8\%) was independent for ADL. Almost all elderly with HF were dependent for ADL ( $n=20 ; 95 \%)$.

It was found that older people were more dependent for bathing (61\%), dressing (58\%), toileting (57\%), transference (57\%), continence (56\%) and feeding (32\%). Similarly, those with a previous diagnosis of $\mathrm{HF}$ had higher dependence for bathing (85\%) and dressing (66\%), as shown in Figure 1.

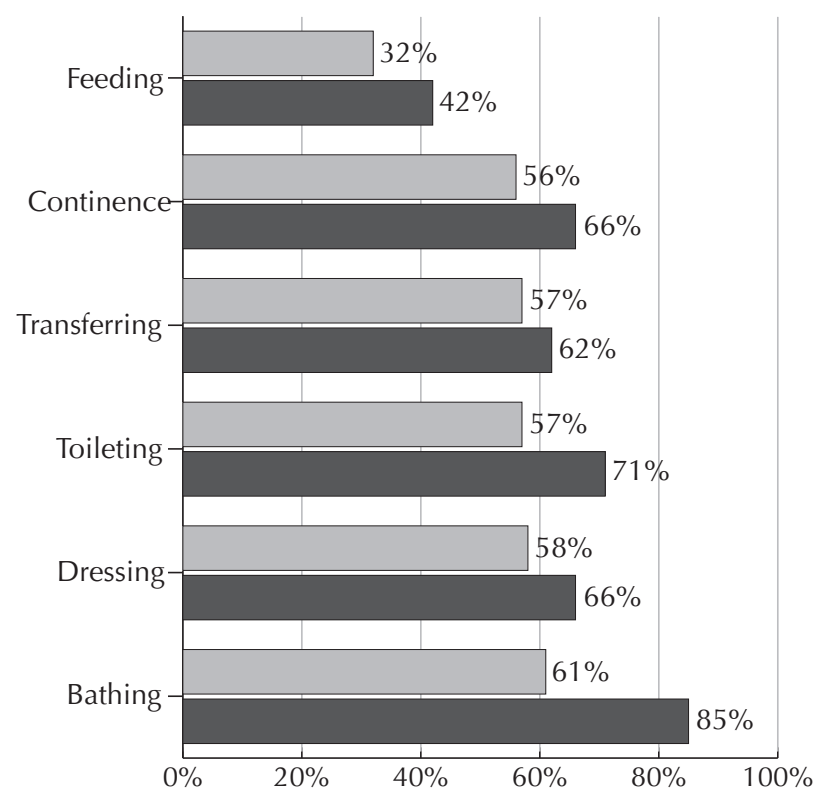

Hospitalized eldery

Hospitalized eldery with diagnosis of HF

Figure 1 - Dependency on Basic Activities of Daily Living in hospitalized elderly - São Paulo, SP, Brazil, 2015.

By analyzing the relationship between $\mathrm{HF}$ and dependency for $\mathrm{ADL}$, it was observed that patients with $\mathrm{HF}$ show a significant reduction of 0.79 points in the Katz index score (95\% CI, 1.61-0.02; $\mathrm{p}<0.05)$. The results of regression analysis of $\mathrm{HF}$ as a predictor of functional dependence are presented in Table 3.

\section{DISCUSSION}

It was shown in this study that HF is a dependence predictor in hospitalized elderly, increasing the chance of functional loss by five times. Still, the elderly with HF considered independent for ADL is 3.5 times more likely to become partially dependent, and in turn they have the same chance of becoming totally dependent. Similarly, having a previous diagnosis of $\mathrm{HF}$ reduces the Katz index score by 0.79 points.

Similar results have been previously observed. In a study conducted in 2014, it was observed that hospitalization for $\mathrm{HF}$ increased the odds of ADL dependency by $40 \%$, presenting itself as an independent predictor of this condition ${ }^{(6)}$. In a prospective observational cohort study designed to evaluate clinical outcomes, functional outcome, quality of life and use of social resources in elderly hospitalized for HF, among the 450 participants it was observed that $118(26 \%)$ had some degree of dependence for ADLs and only 76 (16.2\%) had no trouble walking 400 meters $^{(11)}$. Hospitalized elderly with HF tend to be more dependent.

It can be said that in a comprehensive manner, $\mathrm{HF}$ patients experience changes in their lifestyle due to the inability generated by the signs and symptoms of the disease. In most forms of HF, the reduction in cardiac output is responsible for inadequate tissue perfusion. However, not all seniors will present low ejection fraction ${ }^{(12-13)}$.

Unlike the presentation of HF in young adults, a condition where the systolic dysfunction is the cause of significant pathology in the elderly clinical manifestations often occurs with preserved systolic function of the left ventricle, corroborating findings of this study, and there is therefore higher expressiveness of low $\mathrm{LVEF}^{(14)}$. Thus, other contributing factors should be considered.

There are many reasons that cause these elderly to become more dependent. First, one has to consider that despite the HF, the elderly body undergoes anatomical and physiological changes that culminate in decreased systemic functional reserve and ability to maintain homeostatic balance in adverse situations. These changes, associated with multiple pathologies and polypharmacy potentiate the chance of disability and dependence in the elderly ${ }^{(15-16)}$. This, coupled with the presence of HF, can further increase the risk of morbidity and death of these individuals.

Table 3 - Generalized linear regression models of HF as a predictor for dependency in hospitalized elderly - São Paulo, SP, Brazil, in 2015.

\begin{tabular}{|c|c|c|c|c|c|c|c|c|c|}
\hline & & & \multicolumn{2}{|c|}{ HF } & \multirow[b]{2}{*}{$p$-value* } & \multirow[b]{2}{*}{ B } & \multirow[b]{2}{*}{$p$-value** } & \multirow[b]{2}{*}{ OR } & \multirow[b]{2}{*}{$95 \% \mathrm{CI}$} \\
\hline & & & $\begin{array}{c}\text { No } \\
\mathbf{n}(\%)\end{array}$ & $\begin{array}{c}\text { Yes } \\
\mathbf{n}(\%)\end{array}$ & & & & & \\
\hline \multirow{2}{*}{ Dependence } & Dependent & $\mathrm{n}(\%)$ & $63(63 \%)$ & $20(20 \%)$ & \multirow{2}{*}{0.11} & \multirow{2}{*}{1.62} & \multirow{2}{*}{0.12} & \multirow{2}{*}{5.08} & \multirow{2}{*}{$0.94-94.48$} \\
\hline & Independent & $\mathrm{n}(\%)$ & $16(16 \%)$ & $1(1 \%)$ & & & & & \\
\hline \multirow{3}{*}{$\begin{array}{l}\text { Dependence } \\
\text { Level }\end{array}$} & Totally dependent & $\mathrm{n}(\%)$ & $38(38 \%)$ & $16(16 \%)$ & \multirow{3}{*}{0.07} & \multirow{3}{*}{1.27} & \multirow{3}{*}{0.02} & \multirow{3}{*}{3.57} & \multirow{3}{*}{$1.28-11.66$} \\
\hline & Partially dependent & $\mathrm{n}(\%)$ & $25(25 \%)$ & $4(4 \%)$ & & & & & \\
\hline & Independent & $\mathrm{n}(\%)$ & $16(16 \%)$ & $1(1 \%)$ & & & & & \\
\hline
\end{tabular}


Another important factor to consider is the presence of comorbidities, associated or not associated to $\mathrm{HF}$, as half of the hospitalizations of the elderly are related to the high number of comorbidities and polypharmacy ${ }^{(17)}$. The mean number of comorbidities associated with the diagnosis of HF in this study (4.0) was similar to that found in previous studies ${ }^{(6)}$. However, the prevalence of $\mathrm{HF}$ as a cause of admission to the study was lower than that found previously. The low number of cases admitted for HF in our sample (2\%) may be due to the existence of a cardiology reference service in the same hospital complex of the study, where patients with HF may have been forwarded. The historically found prevalence of HF (21\%) was also lower than other studies. In a study conducted with 51 elderly, with a mean age of 78 years, 16 (31\%) had a previous diagnosis of $\mathrm{HF}^{(18)}$.

In addition, in a study of 4.795 elderly, the proportion of individuals with hospitalization for HF increased by $8 \%$ in individuals aged up to 69 years and $13 \%$ in those who were older. The hospitalized individuals were older, used more drugs, had more comorbidities and more functional limitations ${ }^{(6)}$.

Cardiovascular factors and non-cardiovascular conditions may precipitate the development or worsening of signs and symptoms of HF patients, thus leading to acute episodes requiring hospitalization ${ }^{(19)}$. The prevention of risk factors for cardiovascular disease is critical for patients with HF. The presence of hypertension, an increase of systolic levels, diabetes, and worsening of functional class, etiology of the disease, anemia, obesity and chronic renal failure are risk factors in cardiovascular mortality ${ }^{(8,19)}$.

A relevant finding in the study sample was the high number of diagnoses of depression, affecting $23 \%$ of the participants. Depression, also associated with greater dependence, is a risk factor for developing cardiovascular disease and is common in people with HF, and the association of these two diseases is an evolutionary worsening factor ${ }^{(20)}$. Studies have been conducted to assess the impact of the association between HF and depression symptoms. A survey of 348 participants with a mean age of 68 years, recruited from urban medical centers, revealed that the Body Mass Index (BMI) is closely related to depressive symptoms in patients with HF, especially among women ${ }^{(21)}$. In patients with HF, depression can represent an independent risk factor for mortality and hospitalization, and is associated with higher cognitive impairment ${ }^{(21-22)}$.

Polypharmacy in the elderly is a large risk factor for complications and adverse events. In a cohort study performed with 4.979 individuals with a mean age of 73.8 years, it was found that individuals diagnosed with $\mathrm{HF}$ used more drugs and were characterized by a higher prevalence of comorbid and functional dependence ${ }^{(6)}$. The trend toward polypharmacy was observed in the studied sample, which noted a mean of 10 medications prescribed for the elderly. Polypharmacy can be a contributing factor to greater functional dependence in the studied sample.

Hospitalization itself may be a factor associated to increased dependence of the elderly with $\mathrm{HF}^{(23)}$. During hospitalization, the functional capacity of the elderly can be compromised and lead to functional dependence, culminating in an often irreversible reduced quality of life, especially in the elderly with $\mathrm{HF}^{(6)}$. It has also been shown that older adults diagnosed with $\mathrm{HF}$ and who had permanent bed rest had worse evolutionary results, evidenced by worse prognoses.

Another study showed that the elderly, in the two weeks preceding the period of hospitalization, were totally independent ${ }^{(24)}$. However, after hospitalization, $44 \%$ were unable to walk a block, and 58\% required assistance for one or more Activities of Daily Living (ADL). Still, after admission, $64 \%$ of elderly developed dependence on one or more $\mathrm{ADL}$, and about a quarter were dependent for 4-5 $\mathrm{ADL}^{(24)}$. In a multicenter study of 942 elderly patients diagnosed with HF in ten Spanish hospitals, it was found that the functional deterioration of ADL was advanced, showing that $20.8 \%$ of the elderly had some functional impairment and less than $40 \%$ were fully independent ${ }^{(2)}$.

The number of elderly patients with HF in hospitals is increasing, so that the care for these patients needs to be standardized in nursing care practice in Brazil and worldwide. The elderly with HF have unique characteristics that can distinguish them from other hospitalized elderly patients in terms of care needs. Demographically, it is observed that they are older, aged more than 70 years and there is a higher frequency of women, which is compatible with the feminization of old age $\mathrm{e}^{(6,16,25)}$.

Age seems to be a major independent determinant of heart failure ${ }^{(25)}$. The results showed a predominantly elderly female profile, with multiple comorbidities, using several medicines and mostly dependent. When comparing HF and functional dependence, there was evidence that HF enhances the chance of dependence of the hospitalized elderly, and this is mainly related to the female gender.

They are individuals dependent on nursing for selfcare. As in other studies ${ }^{(26)}$, the results showed that a large number of requests are to carry out activities related to hygiene and comfort, especially bathing. The elderly have diminished physiological reserve, making them vulnerable to situations of functional dependence, which can last beyond hospital discharge. The prevention of dependence or its deterioration should be one of the foci of nursing actions.

The nurse should consider that functional decline is not an inevitable event and not inherent part of senescence. The functional assessment to determine the degree of dependence of the elderly at hospital admission enables a strategic plan for assistance, with improving service for individual care. In the elderly, evaluating the functional capacity and the existence of functional loss predictors, such as HF, is a mandatory part of the systematization of nursing care. Understanding the performance for ADL allows for not only a broad vision of functional impairment for adequate care planning, but also risk prevention and health problems. In addition, the functional loss when this occurs may be indicative of poor quality of life in these individuals.

It was not possible to verify what the impact of hospitalization has on the functional performance in hospitalized elderly compared with medical discharge. In addition, there 
was no record of the functional class of the elderly in their chart, and it was estimated at the time of evaluation based on the New York Heart Association. Despite functional class being a subjective indicator of $\mathrm{HF}$ associated with classification and interpretation bias, it is widely used both in clinical practice and in research ${ }^{(27)}$. Added to the low number of admission cases for HF, these are limitations that must be observed in future studies.

Nevertheless, through this study it was possible to understand the complexity of factors associated with dependence in hospitalized elderly with regard to the presence of HF. Functional decline is common in the lives of this population, and carries with it several limitations. However, it is believed that if they are well taken care of and directed, elderly diagnosed with HF may be able to manage their life and perform ADL with the maximum possible independence. The evaluation of dependency is still a challenge in health care and the impact of associated factors is not sufficiently known. Therefore, assessing the level of dependence during the hospitalization of elderly patients with $\mathrm{HF}$ is mandatory for good nursing practices.

\section{CONCLUSION}

The prevalence of functional dependence in elderly hospitalized with $\mathrm{HF}$ was 95\%, with the more compromised ADL being bathing. HF is a predictor for dependency in hospitalized elderly, increasing the chance of functional loss by five times, the chance of functional deterioration by 3.5 times, and reducing the score of the Katz Index by 0.794 points.

\section{RESUMO}

Objetivo: Identificar se a Insuficiência Cardíaca (IC) é um preditor de dependência funcional para as Atividades Básicas de Vida Diária (AbVD) em idosos hospitalizados. Método: Estudo epidemiológico, observacional em corte transversal. Foram analisados os prontuários e feita avaliação funcional através do Índice de Katz de 100 idosos em uma enfermaria geriátrica de um hospital universitário. Para verificar se a IC é um preditor de dependência funcional, foram feitas análises de regressão linear. Resultados: A prevalência de IC foi de $21 \%$, sendo que $95 \%$ destes, eram dependentes para as AbVDs. Banho foi a AbVD mais comprometida. A IC aumenta em 5 vezes a chance de perda funcional (IC 95\% 0,94-94,48), em 3,5 vezes a chance de piora funcional (IC95\% 1,28-11,66; p < 0,02) e reduz em 0,79 pontos o escore do Índice de Katz $(\mathrm{p}<0,05)$. Conclusão: A IC é um preditor de dependência para AbVDs em idosos hospitalizados, que tendem a ser mais dependentes, principalmente para o banho.

\section{DESCRITORES}

Insuficiência Cardíaca; Idoso; Hospitalização; Atividades Cotidianas; Banho.

\section{RESUMEN}

Objetivo: Identificar si la Insuficiencia Cardiaca (IC) es un pronosticador de dependencia funcional para las Actividades Básicas de Vida Diaria (AbVD) en ancianos hospitalizados. Método: Estudio epidemiológico, observacional en corte transversal. Fueron analizadas las fichas y hecha la evaluación funcional mediante el Índice de Katz de 100 ancianos en una enfermería geriátrica de un hospital universitario. Para verificar si la IC es un pronosticador de dependencia funcional, se hicieron análisis de regresión lineal. Resultados: La prevalencia de IC fue del 21\%, siendo que el 95\% de estos eran dependientes para las AbVDs. E1 baño fue la AbVD más comprometida. La IC aumenta 5 veces la probabilidad de pérdida funcional (IC 95\% 0,94-94,48) y 3,5 veces la probabilidad de empeoramiento funcional (IC95\% 1,28-11,66; p < 0,02); y reduce en 0,79 puntos el puntaje del Índice de Katz ( $<<0,05)$. Conclusión: La IC es un pronosticador de dependencia para AbVDs en ancianos hospitalizados, quienes tienden a ser más dependientes, especialmente para bañarse.

\section{DESCRIPTORES}

Insuficiencia Cardíaca; Anciano; Hospitalización; Actividades Cotidianas; Baños.

\section{REFERENCES}

1. Azad N, Lemay G. Management of chronic heart failure in the older population. J Geriatr Cardiol. 2014;11(4):329-37.

2. Herrero-Puente P, Martín-Sánchez FJ, Fernández-Fernandez M, Jacob J, Llorens P, Miró Ò, et al. Differential clinical characteristics and outcome predictors of acute heart failure in elderly patients. Int J Cardiol. 2012;155(1):81-6.

3. Montero-Perez-Barquero M, Manzano L, Formiga F, Roughton M, Coats A, Rodríguez-Artalejo F, et al. Utility of the SENIORS elderly heart failure risk model applied to the RICA registry of acute heart failure. Int J Cardiol. 2015;182:449-53.

4. Zachariah D, Taylor J, Rowell N, Spooner C, Kalra PR. Drug therapy for heart failure in older patients-what do they want? J Geriatr Cardiol. 2015;12(2):165-73.

5. Norberg EB, Boman K, Löfgren B, Brännström M. Occupational performance and strategies for managing daily life among the elderly with heart failure. Scand J Occup Ther. 2014;21(5):392-9.

6. Skalska A, Wizner B, Więcek A, Zdrojewski T, Chudek J, Klich-Rączka A, et al. Reduced functionality in everyday activities of patients with self-reported heart failure hospitalization: population-based study results. Int J Cardiol. 2014;176(2):423-9.

7. Lo AX, Donnelly JP, McGwin G, Bittner V, Ahmed A, Brown CJ. Impact of gait speed and instrumental activities of daily living on all-cause mortality in adults $\geq 65$ years with heart failure. Am J Cardiol. 2015;15;115(6):797-801. 
8. Bocchi EA, Marcondes-Braga FG, Bacal F, Ferraz AS, Albuquerque D, Rodrigues D, et al.; Sociedade Brasileira de Cardiologia. Atualização da Diretriz Brasileira de Insuficiência Cardíaca Crônica - 2012. Arq Bras Cardiol. 2012;98(1 Supl. 1):1-33.

9. Katz S, Ford AB, Moskowitz RW, Jackson BA, Jaffe MW. Studies oh illness in the aged. The index of ADL: a standardized measure of biological and psychosocial functions. JAMA. 1963;185(12):914-9.

10. Shelkey M, Wallace M. Katz Index of Independence in Activities of Daily Living (ADL) [Internet]. New York: Hartford Institute for Geriatric Nursing, New York University, College of Nursing; 2012 [cited 2015 Jan 27]. Available from: http://consultgerirn.org/uploads/File/trythis/ try_this_2.pdf

11. Vidán MT, Sánchez E, Fernández-Avilés F, Serra-Rexach JA, Ortiz J. FRAIL-HF: a study to evaluate the clinical complexity of heart failure in nondependent older patients: rationale, methods and baseline characteristics. Clin Cardiol. 2014;37(12):725-32.

12. Andersson C, Vasan RS. Epidemiology of heart failure with preserved ejection fraction. Heart Fail Clin. 2014;10(3):377-88.

13. Rose-Jones LJ, Rommel JJ, Chang PP. Heart failure with preserved ejection fraction: an ongoing enigma. Cardiol Clin. 2014;32(1):151-61.

14. Satomura H, Wada H, Sakakura K, Kubo N, Ikeda N, Sugawara Y, et al. Congestive heart failure in the elderly: comparison between reduced ejection fraction and preserved ejection fraction. J Cardiol. 2012;59(2):215-9.

15. Barceló M, Torres O, Ruiz D, Casademont J. Appropriateness of medications prescribed to elderly patients with advanced heart failure and limited life expectancy who died during hospitalization. Drugs Aging. 2014;31(7):541-6.

16. Gyalai-Korpos I, Ancusa O, Dragomir T, Tomescu MC, Marincu I. Factors associated with prolonged hospitalization, readmission, and death in elderly heart failure patients in western Romania. Clin Interv Aging. 2015;10:561-8.

17. Stein GY, Kremer A, Shochat T, Bental T, Korenfeld R, Abramson E, et al. The diversity of heart failure in a hospitalized population: the role of age. J Card Fail. 2012;18(8):645-53.

18. Stoutjesdijk E, Barents M, Brouns RM, DeJongste MJ, Besselink HJ, Cheng JD, et al. Underestimated prevalence of chronic heart failure among the elderly residing in Care Homes in Aruba. West Indian Med J. 2014;63(6). [Epub ahead of print]

19. Farmakis D, Parissis J, Lekakis J, Filippatos G. Acute heart failure: epidemiology, risk factors, and prevention. Rev Esp Cardiol. 2015;68(3):245-8.

20. Gouweleeuw L, Naudé PJ, Dejongste MJ, Eisel UL, Schoemaker RG. The role of neutrophil gelatinase associated lipocalin (NGAL) as biological constituent linking depression and cardiovascular disease. Brain Behav Immun. 2015;46:23-32.

21. Hawkins MA, Dolansky MA, Schaefer JT, Fulcher MJ, Gunstad J, Redle JD, et al. Cognitive function in heart failure is associated with nonsomatic symptoms of depression but not somatic symptoms. J Cardiovasc Nurs. 2014 Jul 22. [Epub ahead of print].

22. Xu SD, Su GH, Lu YX, Shuai XX, Tao XF, Meng YD, et al. Elevated soluble ST2 and depression increased the risk of all-cause mortality and hospitalization in patients with heart failure. Int Heart J. 2014;55(5):445-50.

23. Liu MH, Wang CH, Huang YY, Cherng WJ, Wang KW. A correlational study of illness knowledge, self-care behaviors, and quality of life in elderly patients with heart failure. J Nurs Res. 2014;22(2):136-45.

24. Deborah E, Barnes, Mehta KM, Fortinsky RH, Palmer RM, Kirby KA, et al. Prediction of recovery, dependence or death in elders who become disable during hospitalization. J Gen Intern Med. 2012;28(2):261-8.

25. Metra M, Cotter G, El-Khorazaty J, Davison BA, Milo O, Carubelli V, et al. Acute heart failure in the elderly: differences in clinical characteristics, outcomes, and prognostic factors in the VERITAS study. J Cardiac Fail. 2014;21(3):179-88.

26. Rocha LS, Souza LMS, Rozendo CA. Necessidades humanas básicas e dependência de cuidados de enfermagem de idosos institucionalizados. Rev Eletr Enf [Internet]. 2013 [citado 2015 jan. 27];15(3):722-30. Disponível em: https://www.fen.ufg.br/fen_revista/ v15/n3/pdf/v15n3a14.pdf

27. Pereira DAG, Rodrigues RS, Samora GAR, Lage SM, Alecar MCN, Parreira VF, et al. Capacidade funcional de indivíduos com insuficiência cardíaca avaliada pelo teste de esforço cardiopulmonar e classificação da New York Heart Association. Fisioter Pesq. 2012;19(1):52-6. 